\title{
POLÍTICAS PÚBLICAS E INFRAESTRUTURA: A AGENDA DO SETOR ELÉTRICO BRASILEIRO
}

Hemerson Luiz Pase

\section{Resumo}

O artigo analisa as políticas públicas de infraestrutura do setor elétrico no período pós redemocratização no Brasil. A análise de políticas públicas é utilizada como instrumental teórico e metodológico para interpretar as opções orientadoras e o método de implantação da política energética. O problema de pesquisa investiga como se configura a agenda do setor elétrico brasileiro depois da redemocratização. As conclusões indicam que as políticas públicas de infraestrutura do setor elétrico têm uma agenda de continuidade para garantir a prestação de serviço que num ambiente de mercado necessita de atratividade econômica, cujo critério é a garantia de acumulação.

Palavras-chave: Políticas Sociais; Políticas Compensatórias; Hidrelétricas; Brasil.

\begin{abstract}
The article analyzes the public policy infrastructure of the electricity sector in the post democratization in Brazil. The policy analysis is used as theoretical tools and methodological options to interpret the guidelines and the method of implementation of energy policy. The research investigates the problem of how to set the agenda of the Brazilian electric sector after democratization. The findings indicate that public policy infrastructure of the electricity sector has an agenda to ensure the continued provision of service in a market environment, you need economic attractiveness, whose criterion is the assurance of accumulation.
\end{abstract}

Keywords: Social Policies; Compensation Policies; Hydroelectric; Brazil.

\section{Introdução}

No Brasil o setor de produção energética a partir das hidrelétricas, cuja matriz predomina em nosso território em razão da formação do relevo e abundância de água, originou-se no final do século XIX até a década de 1930 a partir de investimentos privados. A energia elétrica excedente era repassada para o poder público local manter uma rudimentar iluminação pública e/ou movimentar bondes de transporte. Contudo, foi o investimento público direto feito pelo Estado no período que compreende os anos 1930 a 1980 que consolidou e fez crescer a infraestrutura nacional e, particularmente, a oferta de energia. Essa oferta era necessária para movimentar o parque industrial, tanto quanto para possibilitar o processo de 
urbanização e acesso da população a serviços públicos e ao conforto dos bens duráveis.

Na década de 1990 observou-se um movimento no sentido de retomada da atuação privada na produção hidrelétrica através da opção que o Estado brasileiro realiza no sentido de se retirar de alguns setores econômicos repassando-os à iniciativa privada. Este movimento coincide com o processo de redemocratização brasileiro (final da década de 1980), período em que o país vivia um processo de crescentes índices inflacionários e de um completo descontrole fiscal e financeiro comprometendo o orçamento público com uma dívida externa crescente e com políticas sociais centralizadas e ineficientes, em razão da concepção autoritária, centralizadora e antifederalista dos governos militares. No período imediatamente recente ocorreu uma retomada do protagonismo do Estado em relação às políticas públicas energéticas em razão da reconfiguração das relações de poder vencedoras das eleições majoritárias em 2002.

Este artigo tem o objetivo de analisar as políticas públicas de infraestrutura do setor elétrico no período contemporâneo, quando o país experimenta o processo de redemocratização onde existe espaço para variados segmentos sociais participarem do processo político decisório.

Será utilizada a análise de políticas públicas como instrumental teórico e metodológico para abordar as opções teóricas orientadoras e o método de implantação da política energética contemporânea no Brasil. Neste sentido discute-se a trajetória histórica da produção energética brasileira. Não obstante, a análise das políticas públicas a partir das abordagens do tipo de política, ciclo da política neoinstitucionalista e da cultura política, permitem perceber que a ação do Estado brasileiro raramente parte do zero; exige articulações sociais e políticas na sua definição, bem como implementação; necessita de amparo e fortalecimento institucional; e, crescentemente, precisa adequar-se e/ou antecipar-se à cultura política e aos estilos políticos dos diferentes grupos sociais e/ou regiões.

O problema de pesquisa investiga como se configura a agenda do setor elétrico brasileiro na redemocratização. A hipótese afirma que a agenda das políticas públicas do setor elétrico é formada sem rupturas significativas objetivando a garantia da prestação de serviço que, por sua vez, num ambiente de mercado, é garantido pela atratividade econômica do setor.

Neste sentido o artigo está organizado em três seções. A primeira discute a concepção teórica da análise de políticas públicas que servirá como aporte metodológico para analisar as políticas de infraestrutura elétrica no Brasil. A segunda seção faz um resgate histórico das políticas energéticas no Brasil com destaque para aquelas de produção hidrelétrica, já que o tamanho do território e a conformação topográfica do país favorecem essa matriz. A terceira seção analisa as políticas públicas do setor elétrico no período contemporâneo destacando as possibilidades interpretativas da abordagem teórica das políticas públicas. 
Importante destacar que o artigo é fruto das reflexões no âmbito do Projeto de pesquisa e desenvolvimento Avaliação dos resultados e proposição de modelo de elaboração de programas de remanejamento de populações atingidas por empreendimentos hidrelétricos, financiado pelo Programa P \& D da BAESA - Energética Barra Grande, regulamentado e fiscalizado pela Agência Nacional de Energia Elétrica (ANEEL).

\section{A análise das políticas públicas}

O conceito de política pública não é inequívoco, pois oscila de acordo com o enfoque teórico adotado e o contexto político e social ao qual ele se aplica, usualmente é identificado com programas ou projetos que determinam ações específicas do Estado. De outro lado, a análise de políticas públicas diz respeito a uma área acadêmica e científica com abordagem teórica e metodológica sobre a política pública. Mesmo marcado pela falta de institucionalização, fragmentação e incipiência, o campo de estudos das políticas públicas apresentou formidável expansão nas últimas décadas. Adquiriu progressivamente sua autonomia como disciplina no interior da Ciência Política e, atualmente, dispõe de razoável acervo de conhecimentos que concebe aos estudos de política pública importante potencial no apoio a intervenções na realidade social.

A expressão políticas públicas parece ter entrado definitivamente no vocabulário contemporâneo e principalmente na vida cotidiana dos países democráticos. Sua presença é constante na imprensa, nas agendas públicas, nos pronunciamentos políticos e nas pautas de reivindicações dos movimentos sociais (DI GIOVANNI, 2009). Por mais óbvio que pareça ao imaginário coletivo, as políticas públicas envolvem a produção de bens públicos, cabendo ao Estado a garantia de políticas que se processam oriundas de diversos interesses, necessidades e demandas de dada população que vive em determinado território (RODRIGUES, 2010).

Entretanto, tamanha simplicidade ou minimalismo conceitual não espelha as múltiplas correntes teóricas e variantes conceituais que o termo adquiriu no interior da Ciência Política ao longo dos últimos anos. De acordo com Di Giovanni (2009), o conceito de políticas públicas é algo evolutivo, na medida em que se refere às relações entre estado e sociedade, determinadas por constantes transformações históricas e permeadas por mediações de natureza variada.

Como aponta Souza (2006, p. 24), "não existe uma única, nem melhor, definição sobre o que seja política pública". Mead a define como um campo de análise política que observa o governo à luz de grandes questões públicas e Lynn, como um conjunto de ações do governo que irão produzir efeitos específicos. Para Peters, política pública corresponde à soma das atividades dos governos, que agem diretamente ou através de delegações, influenciando a determinado modo, a vida dos cidadãos (SOUZA, 2006). Norberto Bobbio (apud RODRIGUES, 2010) define políticas públicas como a 
intervenção do Estado no ordenamento da sociedade por meio de ações jurídicas, sociais e administrativas.

Todavia, as definições conceituais de políticas públicas mais difundidas no meio acadêmico compreendem as dispostas por Thomas Dye e Harold Laswell. Dye (apud ROMANO, 2009, p. 14), sintetiza a definição de política pública como "o que o governo escolhe fazer ou não", implicando questionamentos sobre o que o governo, em suas interações políticas com os atores da sociedade civil e do mercado escolhe fazer ou deixar de fazer; por que o faz; como faz; que diferença suas escolhas fazem; e quem se beneficia com esse fazer. Já Laswell (apud SOUZA, 2006, p. 24), afirma que decisões e análises sobre políticas públicas implicam responder a questões do tipo: quem ganha o quê; por quê; e que diferença isso faz.

Mesmo que o tempo e a história não tenham proporcionado singularidade, ou não evidenciaram a melhor definição conceitual para as políticas públicas, é importante notar que as distintas abordagens teóricas do campo de análise de políticas públicas evidenciadas anteriormente, guiam o olhar para o locus onde os embates em torno de interesses, preferências e idéias se desenvolvem, isto é, o Governo (SOUZA, 2006).

Embasadas nas abordagens anteriores, outras teorizações a respeito da definição conceitual de políticas públicas surgiram. Como exemplo, Di Giovanni (2009) sustenta que uma política pública não consiste simplesmente em uma intervenção do Estado a uma situação social considerada problemática. Pensa a política pública como uma forma contemporânea de exercício do poder nas sociedades democráticas, resultante da interação entre Estado e sociedade, onde tamanha proximidade define as situações sociais consideradas problemáticas, os conteúdos e as modalidades da consequente intervenção estatal.

Por esse mesmo viés, Romano (2009) afirma que as políticas públicas se constituem no dispositivo de governo responsável pela importante relação do Estado com a sociedade e o mercado. Para o autor, as políticas públicas acabam por assumir uma função estratégica ao: definirem os parâmetros e as modalidades de interação entre o público e o privado; permitirem visualizar o nível de autonomia da ação pública e; ao definir quais os assuntos que alcançam o status de interesse público, ou seja, quais políticas que serão introduzidas na agenda de ação do governo ${ }^{1}$.

Nota-se que as últimas concepções de políticas públicas evidenciam grande envolvimento de outros segmentos, que não os do governo, por meio de processos interacionais que acabam influenciando a formulação das políticas. Todavia, apesar do reconhecimento de que grupos de interesse e movimentos sociais, cada qual com menor ou maior influência, podem envolver-se no processo das políticas públicas, e apesar de certa literatura argumentar que o papel dos governos tenha sido encolhido, a diminuição da

\footnotetext{
1 Para definições acerca de como questões passam a integrar a agenda de políticas de determinado governo, consultar Capella (2010).
} 
capacidade dos governos de intervir, formular políticas públicas e governar não está empiricamente comprovada (SOUZA, 2006).

Apoiada sobre o viés da supremacia estatal em relação a influências externas e internas na definição das políticas, Souza (2006) afirma que podese, então, resumir política pública como o campo do conhecimento que busca, ao mesmo tempo, "colocar o governo em ação" ${ }^{2}$ e/ou posteriormente analisar essa ação e, quando necessário, propor mudanças nos rumos ou cursos de tal política. Constituindo a formulação de políticas públicas um estágio em que governos democráticos traduzem seus propósitos e plataformas eleitorais em programas e ações que produzirão mudanças na realidade social.

Os modelos explicativos das políticas públicas são inúmeros, bem como suas variações analíticas, e abordá-los em sua totalidade é tarefa tortuosa. Portanto, o estudo sintetiza somente alguns modelos empenhados em elucidar os processos de formulação, implementação e resultados das políticas. Considera-se os seguintes modelos: a tipologia de política, o ciclo das políticas, da teoria das redes, o neoinstitucionalismo e a análise de estilos políticos.

O pressuposto analítico que regeu o advento e consolidação de estudos sobre políticas públicas foi o de que, em democracias estáveis, aquilo que o governo faz ou deixa de fazer é passível de ser formulado cientificamente e analisado por pesquisadores independentes (SOUZA, 2006). Ao passo que essa máxima foi adotada pela academia, desenvolveram-se inúmeros modelos explicativos empenhados em elucidar os processos de formulação, implementação e avaliação das políticas.

Reis (2003) atenta para a necessidade de clareza para o analista de políticas públicas, tanto em relação ao modelo explicativo na qual insere seu trabalho, quanto em relação às discussões que confrontam a perspectiva adotada e as alternativas teóricas a ela. Nas palavras da autora, "isso é condição básica para que o diálogo intelectual seja frutífero" (REIS, 2003).

$\mathrm{Na}$ tentativa de "lançar luz" sobre os modelos analíticos do campo das políticas públicas e contribuir para "abundância" de posteriores análises, essa observação procura elencar os variados prismas teóricos que moldam as explicações de como ou porque o governo executa ou abstém-se de determinada ação política.

\subsection{Tipologia das políticas públicas (policy arena, arenas de poder)}

Para elaborar a diferenciação entre as distintas formas que podem adotar as políticas públicas, Theodore J. Lowi $(1964,1972)$ partiu do pressuposto de que as reações e expectativas das pessoas afetadas pelas políticas desenvolvidas por determinado governo possuem um efeito antecipativo para o processo político de decisão e implementação (FREY,

\footnotetext{
2 Termo cunhado por Jobert e Müller para definir as políticas públicas (TREVISAN e BELLEN, 2008).
} 
2000). Ou seja, cada tipo de política pública vai encontrar diferentes formas de apoio ou rejeição, dependendo do impacto que cada política pretende sobre a população atingida (ROMANO, 2009).

Para Lowi é a política pública, enquanto resultado momentâneo da ação do Estado materializado pelo jogo que se estabelece no sistema político, que produz a política, enquanto processo de conflito, disputa e acordo para a realização de interesses e preferências, acesso a recursos, bens e direitos.

Tomando por base os processos de consenso e conflito ocasionados pelas diferentes ações do governo nas diversas áreas da política, os respectivos conteúdos de cada política, e seus meios de implementação, Lowi estruturou a diferenciação das políticas públicas de acordo com quatro formatos: distributivas, redistributivas, regulatórias e constitutivas (FREY, 2000; SOUZA, 2006; ROMANO, 2009; RODRIGUES, 2010).

Por políticas distributivas, o autor caracterizou as decisões de governo que visam distribuir "vantagens" a determinado grupo social ou região, sem afetar negativamente ou acarretar custos ao montante da população não beneficiada, gerando impactos mais individuais do que universais. Tais políticas são caracterizadas pelo baixo grau de conflito ocasionado por sua implantação a determinado grupo e por processos de indiferença amigável de quem não foi beneficiado (FREY, 2000; SOUZA, 2006). Contudo, nas palavras de Romano (2009, p. 45), as políticas distributivas, "com a alocação de recursos facilmente divisíveis, proporcionam relações e estruturas de clientelismo, patronagem e acordos de soma positiva efêmeros".

De outro modo, as políticas redistributivas buscam deslocar recursos financeiros, direitos ou outros valores entre diferentes camadas sociais ou grupos da sociedade (WINDHOFF-HÉRITIER, apud FREY, 2000). Nota-se que estas modificam a distribuição de recursos pré-existente, impondo perdas concretas para certos grupos sociais e ganhos incertos para outros (SOUZA, 2006). Os segmentos afetados por essas políticas são muito mais amplos, por referirem-se a oposição entre os distintos lugares que os atores sociais ocupam, inclusive, na estratificação social (classe baixa e classe alta; burgueses e proletários; pequenos e grandes empreendedores). Tais políticas são planejadas e materializadas dando grande ênfase a focalização e condicionalidades. A focalização diz respeito à definição do segmento social ou delimitação terrritorial que terá acesso e a condicionalidade diz respeito ao conjunto de condições que os beneficiários precisam ter e manter para acessarem e manterem-se como tal. Nesse sentido, pode-se imaginar quão conflitiva e polarizada é a natureza de uma política redistributiva (RODRIGUES, 2010).

As políticas regulatórias definem a fronteira entre "quem ganha e quem perde", regulando os efeitos referentes aos custos e benefícios oriundos da configuração concreta de determinada política por meio da elaboração de ordens e proibições, garantidas por leis, decretos e portarias (FREY, 2000, p. 7). Por envolverem a burocracia estatal, grupos de interesse e grupos políticos, são decisões mais visíveis ao público e redundam principalmente em 
decisões que regulamentam setores econômicos e de serviços, como exemplo, telecomunicações, aviação civil e distribuição energética (SOUZA, 2006; RODRIGUES, 2010).

Por fim, as políticas constitutivas visam à ordenação do sistema, dos processos e conflitos políticos. Ou seja, proporcionam mudanças nas "regras do jogo" político ou institucional, como a modificação do sistema de governo ou do sistema eleitoral, a determinação dos processos de negociação, cooperação e consulta entre os atores políticos, a criação e modelação de novas instituições que, no caso brasileiro, necessitam de Emendas Constitucionais. Embora essas políticas possam implicar em grandes consequências para o processo político, raramente envolvem a discussão entre setores mais amplos da sociedade, restringindo-se somente a "redoma" político-administrativa (FREY, 2000).

O marco analítico comum para as distintas políticas e programas de governo elaborado por Lowi ressaltou a importância do espaço governamental, ao demonstrar que os poderes públicos dispunham de variados instrumentos para dar conta de diferentes temas, demandas segundo seus objetivos de manutenção ou mudança do status quo.

\subsection{Ciclo das políticas (policy cicle)}

O modelo do ciclo das políticas públicas é amplamente discutido por especialistas para compreender o processo de formação das políticas. De acordo com esse modelo, as políticas públicas são formadas por um conjunto de "etapas" que visam atender as demandas e interesses da sociedade (RODRIGUES, 2010).

Essas etapas vão desde o enfrentamento de determinado problema pela administração pública, até a posterior análise dos efeitos gerados pela solução aplicada. Algumas vertentes do ciclo das políticas focalizam mais os participantes do processo decisório, e outras, o processo de formulação da política (SOUZA, 2006). As tradicionais divisões do ciclo das políticas públicas se diferenciam apenas gradualmente, sendo comum as etapas de formulação, implementação e controle dos impactos das políticas públicas. Entretanto, optou-se aqui pela distinção elaborada por Frey (2000, p. 226), onde assegura que o ciclo das políticas públicas é constituído pela percepção do problema; agenda setting; elaboração de programas; implementação da política; avaliação da política e a eventual correção da ação.

\section{Percepção do problema}

Nessa etapa o Governo decide enfrentar determinado problema e buscar algum tipo de solução para a situação que produz privação, necessidade ou insatisfação. As questões que devem ser observadas pelos decisores nessa etapa são: o problema realmente existe? O Governo deve mobilizar-se e de que maneira? Existem mobilizações externas (grupos 
sociais, empresas, políticos) para introduzir o problema na agenda do Governo? (RODRIGUES, 2010).

É importante salientar que um fato pode ser percebido, pela primeira vez, como um problema político por grupos sociais, por políticos, pela própria administração pública e, igualmente, pela mídia e outras formas de comunicação social. Tornando essa etapa fundamental para o processo decisório, na medida em que diversos atores entram em confronto para incluir os problemas na agenda governamental (RODRIGUES, 2010). Entretanto, problemas só entram na agenda a partir do momento em que adquirem relevância do ponto de vista político-administrativo (FREY, 2000).

A teoria dos grupos de interesse, oriunda do modelo pluralista, é importante para essa abordagem pois afirma que o processo de formulação das políticas públicas é resultado da interação de diversos grupos sociais, que em conflito e intercâmbio acabam por pressionar o governo a determinada ação. Os grupos de interesse não só fazem a articulação de demandas frente aos partidos políticos, como também participam da definição e execução das políticas públicas tencionando pela aprovação de propostas que thes beneficiem direta ou indiretamente ou rejeição daquelas que thes prejudiquem.

\section{Agenda setting}

Nesse momento, o problema pelo qual o Governo decidiu agir torna-se uma questão política (issue) e adquire status de problema público. A partir daqui as decisões sobre o problema resultarão no desenho de políticas ou programas que, realmente, serão implementados na etapa seguinte (RODRIGUES, 2010). A pergunta que merece atenção aqui é: por que um problema se torna importante em um determinado momento, ao ponto de chamar a atenção do governo e integrar sua agenda política?

Segundo Capella (2010), dois modelos destacam-se por sua capacidade de explicar como as agendas governamentais são formuladas e alteradas: o Modelo de Múltiplos Fluxos (Multiple Streams) e o Modelo de Equilíbrio Pontuado (Punctuated Equilibrium Model). O primeiro com raízes no modelo de análise de políticas públicas intitulado "Garbage Can", evidencia que algumas questões são bem sucedidas no ingresso à agenda governamental quando os fluxos de problemas, soluções e fluxo politico ${ }^{3}$ convergem, abrindo espaço para que problemas atraiam a atenção dos

\footnotetext{
3 Em uma explicação bastante sintética Faria (2003) afirma que: "o primeiro [fluxo de problemas], é formado por informações sobre uma variedade de questões problemáticas e por atores que compõem diversas e conflitantes definições para os problemas. O segundo [fluxo de soluções], envolve aqueles que propõem soluções aos distintos problemas. O terceiro [fluxo político],agrega três elementos - movimentação dos grupos de pressão, mudanças no legislativo e nas agências administrativas" (FARIA, 2003, p. 25). Para maiores teorizações, consultar Capella (2010, p. 87-110), em especial, Figura 1 (p. 98).
} 
empreendedores políticos (policy entrepreneurs) e proporcionem consequentes mudanças.

O Modelo de Equilíbrio Pontuado pode ser sintetizado na premissa de que a política pública se caracteriza por longos períodos de estabilidade, interrompidos por períodos de instabilidade que geram mudanças nas políticas anteriores. Para que um problema chame a atenção do governo é necessário que novas idéias surjam ${ }^{4}$, tornem-se populares e se disseminem, permitindo que o entendimento acerca da política seja comunicado de forma simples e direta entre os membros de certa comunidade, contribuindo para mudanças rápidas e acesso de uma questão a agenda de governo (CAPELLA, 2010).

Ou seja, um problema ou tema se estabelece na agenda política (setting) quando os governos identificam a necessidade de fazer algo.

\section{Elaboração ou formulação de programas}

Nessa etapa a discussão gira em torno da escolha mais apropriada entre as várias alternativas propostas para a resolução do problema que ingressou na agenda de governo. As políticas públicas são materializadas através de programas, projetos e ações que exigem amparo institucional, administrativo e financeiro. Para que o programa saia do papel é necessário a realização de levantamentos, análises e disseminação de informações sobre o problema a ser corrigido, posteriormente dá-se a elaboração do programa, decidindo sobre quais benefícios ou serviços serão implementados e de onde serão extraídos os recursos para sua implementação (RODRIGUES, 2010, p. 50-51).

\section{Implementação da política}

Em termos gerais, o processo de implementação significa a aplicação da política pública, efetuada pela burocracia estatal. Essa etapa conduz aos resultados finais das políticas, programas ou projetos. Contudo, para que a política seja implementada de maneira adequada torna-se necessário relacionar o problema à solução proposta (RODRIGUES, 2010), caso contrário, os resultados e impactos de certas políticas podem não corresponder aos impactos projetados na fase de elaboração do programa (FREY, 2000).

Considerando que imprevistos surgem durante a implementação de programas ou políticas representando, por vezes, obstáculos instransponíveis e o consequente "abandono" da ação pelas agencias governamentais, o processo de implementação revela-se como elemento chave nas discussões sobre a eficiência e eficácia de determinada política pública (MELO e SILVA,

\footnotetext{
${ }^{4}$ Conjunto de ideias que sustentam o arranjo institucional, denominadas policy images (CAPELLA, 2010, p. 112).
} 
2000). Uma das mais interessantes discussões trata da direção do fluxo de decisões no processo de planejamento e implementação de políticas públicas.

Análises do tipo Top Down (de cima para baixo) asseguram que decisões quanto ao rumo de certa política pública são tomadas por autoridades que possuem certo controle do processo e decidem o que e como serão implementadas as políticas. A visão Botton Up (de baixo para cima), de certa forma antagônica à anterior, enfatiza a importância daqueles que encontram-se mais próximos das ações resultantes de políticas públicas. Assim, a população afetada por certa política e os agentes do Estado em contato com ela poderiam e deveriam influenciar de forma mais intensa 0 processo de planejamento e implementação (OLIVEIRA, 2006).

\section{Avaliação da política}

Por fim, a etapa de avaliação consiste na análise, in company e ou a posteriori, dos efeitos produzidos por determinada política pública. A atividade de avaliar resultados da política ou programa concentra-se nos processos e efeitos gerados, oferecendo subsídios que possibilitem perceber em que medida as metas foram, de fato, atingidas (RODRIGUES, 2010) e, se necessário, promover a correção de déficits e impactos indesejados para políticas e programas futuros. No caso da atenção ou alcance das políticas objetivadas inicialmente, o processo de avaliação e controle dos impactos pode conduzir a suspensão ou ao fim do ciclo político, caso contrário, pode determinar a iniciação de um novo ciclo ou a modificação do programa anterior (FREY, 2000).

$\mathrm{Na}$ concepção do ciclo das políticas (policy cicle) o processo para resolução de um problema tem uma sequência de fases. Na prática, segundo Frey (2000), os atores político-administrativos dificilmente se fixam a esse contínuo, especialmente para programas políticos mais complexos que se baseiam em processos interativos, cuja dinâmica é movida por reações mútuas dos atores envolvidos.

\subsection{Modelo Neoinstitucional}

O modelo neoinstitucional apenas recentemente tem sido utilizado como abordagem metodológica para a análise de políticas públicas. Para alguns, essa utilização tardia se deve ao fato que a análise de políticas públicas enquanto possibilidade analítica da ação do Estado surge, originalmente, em países consolidados institucionalmente, no caso os Estados Unidos da América, o que dispensaria esse tratamento. No entanto, quando se reflete sobre contextos de fragilidade institucional, como o dos países pobres, em particular da América Latina, África e Ásia, essa perspectiva é adequada.

Para os neoinstitucionalistas, as instituições governamentais possuem importância crucial para a decisão, formulação e implementação de políticas 
públicas. Adquirem notável papel no momento em que são responsáveis pela manutenção de regras gerais e entendimentos que prevalecem sobre cada sociedade, exercendo influência decisiva em interpretações e no próprio agir das pessoas. Possuem ainda, duas virtudes principais: diminuem os custos de decisão ao dispensar grandes esforços para mapear as possibilidades de ação e, de outro lado, estimulam e exigem previsibilidade do comportamento premiando ou sancionando as ações adequadas ou inadequadas. É fato que os atores políticos e sociais agem de acordo com seus próprios interesses, entretanto, as regras, deveres e direitos estimulados e garantidos pelas instituições formais do Estado, como o congresso, a presidência, o judiciário, as burocracias estatais, influenciam o ator político nas suas decisões e na sua busca por estratégias apropriadas (FREY, 1999).

Isso significa afirmar que os atores políticos e sociais não agem somente de acordo com seus interesses pessoais, mas regrados por instituições que oferecem estabilidade ao processo das políticas públicas, coordenando os recursos cognitivos, mediando conflitos e oferecendo incentivos a certas ações políticas (ROMANO, 2009). Cabendo salientar, segundo Souza (2006), que as instituições influenciam os resultados das políticas públicas no instante em que tornam o curso de certas políticas mais fáceis do que outras.

Sendo assim, a teoria neoinstitucionalista ilumina o entendimento de que não são só os indivíduos ou grupos sociais que detêm a força relevante na influência do rumo de certas políticas públicas, mas, igualmente, as regras formais e informais que regem as instituições podem conduzir a certa direção e privilegiar determinados grupos, em detrimento de outros (SOUZA, 2006).

\subsection{Análise de estilos políticos}

Essa vertente analítica aproxima-se da análise de políticas públicas de forma semelhante ao neoinstitucionalismo, em razão das limitações das abordagens tradicionalmente utilizadas. Sob a análise de estilos políticos entende-se o exame de estruturas de decisão a partir de fatores culturais, padrões de comportamento e atitudes que influenciam os atores políticos na implementação de determinada política pública em detrimento de outras (FREY, 1999). Ou seja, o comportamento ou "estilo de ação" do político em relação a certa política pública é influenciado por ideologias, princípios, crenças e valores adquiridos no decorrer de sua socialização política.

Para Frey a análise de estilos políticos é inspirada na cultura política, embora aí não se esgote.

Os elementos definidores do comportamento político são condicionantes considerados pela teoria da cultura política, que surgiu a partir da década de 1950, buscando cobrir lacunas explicativas quanto às dimensões da crise econômica, social e política que assolava o mundo naquele pósguerra. Objetivando fornecer os instrumentos metodológicos necessários à compreensão sistemática das orientações e comportamentos políticos dos 
cidadãos, a teoria da cultura política englobou variáveis como ideologia política, opinião pública e personalidade política (BAQUERO e PRÁ, 2007).

$O$ conceito de cultura política passou por redefinições em virtude de sua importância para o processo de construção democrática e seu papel na legitimação das autoridades públicas e do próprio regime democrático. Como o efetuado por Baquero e Prá (2007), ao entenderem que cultura política pode ser definida como o conjunto de crenças e valores que os cidadãos incorporam ao longo do tempo, e sua capacidade de adaptar esses comportamentos numa perspectiva racional para alcançar determinados objetivos ou aprender a sobreviver politicamente.

Entretanto, para Frey (2000), somente a abordagem da cultura política dificilmente pode fornecer explicações satisfatórias e definitivas sobre o estilo político e realizações materiais das políticas públicas concretas. Assim como crenças e valores incorporados influenciam o agir político, do mesmo modo, tradições regionais e nacionais, estruturas políticas, grau de desenvolvimento econômico, ideologias e treinamento cívico influenciam estilos específicos de políticas. Para o autor, a contribuição da cultura política consiste em atrair a atenção para a variedade de elementos que devem ser considerados na avaliação de estilos políticos (FREY, 2000).

Pode-se distinguir dois objetivos principais da análise de estilos políticos, cujo primeiro consiste em investigar possíveis fatores que podem levar à consolidação de certo estilo de política, como: composição étnica da população, estruturas partidárias e associativas, condições institucionais, estruturas sociais e econômicas. O segundo observa a questão de como programas e políticas públicas podem ser influenciados por estilos políticos concretos. Como exemplo, a implementação de políticas públicas de geração de emprego e renda, ora realizado por governo de caráter participacionista, ora realizado por governo de caráter tecnocrata, impondo o projeto de cima para baixo, conforme critérios exclusivamente técnicos (FREY, 2000).

\section{O setor elétrico brasileiro}

O Brasil tem potencial para a exploração de uma gama enorme de fontes de energia tanto renováveis (hidrelétrica, biomassa, eólica, solar, biogás, geotérmica, marítima) quanto as não renováveis (gás natural, derivados de petróleo, nuclear, carvão mineral). Dentre as possibilidades de geração de eletricidade, a fonte hidrelétrica corresponde a aproximadamente $72 \%$ da capacidade instalada e $85 \%$ do consumo brasileiro (ANEEL, 2008).

O primeiro condicionante da produção hidrelétrica é o fato do Brasil concentrar em seu território aproximadamente $12 \%$ da água doce superficial do planeta, cuja abundância hídrica está associada ao predomínio do relevo planáltico. Esses fatores conferem claramente uma vocação para produção energética a partir de hidrelétricas.

O desenvolvimento do setor elétrico e hidrelétrico foi fortemente influenciado pelas configurações políticas, econômicas e sociais peculiares ao 
Brasil e, em grande medida, similares ao conjunto dos países da América Latina, bem como a inserção do país no capitalismo mundial.

O setor hidrelétrico compreende três segmentos que vão desde a geração até o consumo da energia. O primeiro setor, mais burocrático, seria o de planejamento, que vai atuar nos estudos sobre a viabilidade dos projetos considerando a perspectiva da engenharia (civil, mecânica), economia (custos, financiamentos), política (viabilidade social), jurídica (aspecto legal do processo de instalação e operação) e ambiental (elaboração de Estudo de Impacto Ambiental-EIA). O segundo é o da construção civil, responsável pela instalação física da usina, de equipamentos como subestações e linhas de transmissão. E o terceiro seria o de equipamentos, que pode responder pela produção e comercialização tanto das turbinas que gerarão a energia, como dos eletrodomésticos que consumirão esta mesma energia (PASE e ROCHA, 2010).

O início da exploração hidrelétrica brasileira ${ }^{5}$ ocorreu através de organizações privadas de atuação local com duas empresas que predominaram no cenário nacional nos primeiros anos. A Brazilian Traction Light \& Power (LIGHT) que através de várias empresas filiadas e subsidiárias concentrou seus serviços nas regiões do Rio de Janeiro e de São Paulo, enquanto as Empresas Elétricas Brasileiras, filial da American \& Foreign Power Company (AMFORP), a partir de 1927 passou a atuar em regiões do Nordeste, na Bahia, no interior do estado de São Paulo, parte de Minas Gerais, além dos estados sulinos do Paraná, Santa Catarina e Rio Grande do Sul (PRADO JÚNIOR, 2004). Essa empresa, a AMFORP, entrará no mercado hidrelétrico do México no mesmo período (LEME, 2009).

Conforme Pase e Rocha (2010) o Grupo Light, de origem canadense, foi instituído oficialmente no Brasil em 1899 em São Paulo e no Rio de Janeiro, já a AMFORP, empresa do grupo norte-americano Electric Bond \& Share Corporation (EBASCO) ligado à General Eletrict, se instalou no interior paulista em 1927 através da aquisição de pequenas empresas locais fundidas na Companhia Paulista de Força e Luz (CPFL). Posteriormente a empresa se expandiu para outros estados brasileiros adquirindo empresas locais de cidades importantes como em Natal, Maceió, Recife, Salvador, Vitória, Niterói, São Gonçalo, Petrópolis, Belo Horizonte, Curitiba e Porto Alegre.

Os reflexos da crise da superprodução norte-americana que culminou com o crack da Bolsa de Valores de Nova Iorque afetaram o Brasil, que no início da década de 1930 vivia a crise da superprodução cafeeira que antecedeu a Revolução de 1930, a qual levou Getúlio Vargas ao poder. A política de industrialização e nacionalismo de Vargas atingiu o setor energético, tido como estratégico. O processo de industrialização brasileiro tinha na disponibilidade de energia um dos obstáculos as serem superados,

\footnotetext{
${ }^{5}$ A primeira usina hidrelétrica de energia (UHE) no território brasileiro foi instalada em $1883 \mathrm{em}$ Diamantina (MG). Com 0,5 MW de potência e $2 \mathrm{~km}$ de linhas de transmissão, a UHE Ribeirão do Inferno (afluente do rio Jequitinhonha) foi instalada e explorada pela mineradora Santa Maria, então autoprodutora, conforme Pase e Rocha (2010).
} 
pois o carvão de pedra, combustível principal da indústria moderna, tinha pouca qualidade e era de difícil exploração. Juntamente com a industrialização, a urbanização aumentava a demanda de energia, e a hidroeletricidade aparecia como alternativa mais plausível para o caso brasileiro. Neste contexto, tanto a Constituição brasileira como o Código de Águas (Decreto Federal no 24.643, de 10 de julho), ambos de 1934, caracterizaram-se como leis intervencionistas, segundo as quais, o Estado detinha o controle das águas que poderiam ser exploradas através de concessão. Situação que irá se aguçar na Constituição de 1937, onde o governo Vargas ratifica as medidas de 1934, além de enfatizar a nacionalização de setores essenciais.

As Unidades da Federação entraram de forma congruente nesse processo. Em 1943 foi criada no Rio Grande do Sul a Comissão Estadual de Energia Elétrica (CEEE), em 1945 o estado do Rio de Janeiro organizou a empresa Fluminense de Energia Elétrica, também em 1945 se cria a Companhia Hidroelétrica de São Francisco (CHESF), entre Alagoas e Bahia. Em 1952 o governo mineiro criou as Centrais Elétricas de Minas Gerais (CEMIG) e em 1957 foi criada FURNAS - Centrais Elétricas S.A., consorciando o governo federal, os estaduais paulistas e mineiros, a LIGHT e a CPFL. Com o objetivo de arrecadar recursos para a expansão do setor, foi criado em 1953 o Fundo Federal de Eletrificação, que seria controlado pelo então Banco Nacional de Desenvolvimento Econômico (BNDE, atual BNDES).

No governo de Juscelino Kubitschek, em 1960, foi criado o Ministério de Minas e Energia, e em 1961 foi aprovada pelo Congresso a criação da ELETROBRAS (Centrais Elétricas Brasileiras S.A.), instalada em 11 de junho de 1962. Já no governo de João Goulart, a empresa seria organizada em quatro subsidiárias regionais - CHESF (Nordeste), Furnas (Sudeste), ELETROSUL (Sul) e a ELETRONORTE (Norte), além de duas empresas controladas de âmbito estadual, a Light Serviços de Eletricidade S.A. e a Excelsa.

No período de 1968-73 a industrialização e urbanização aumentavam a demanda de energia agravada pela crise do petróleo de 1973 que aumentava a importância dos projetos hidrelétricos. Por esta razão o governo Geisel reafirma a prioridade da hidroeletricidade como alternativa ao problema do petróleo. Ao mesmo tempo em 1978, o governo compra a Light, que passa a ser controlada pela ELETROBRAS em 1979.

A partir deste momento, o setor hidrelétrico brasileiro se consolidou através da articulação industrial de três segmentos: de estudos e projetos, de construção civil e de equipamentos elétricos. Empresas como a ENGEVIX, Camargo Corrêa, a Alstom e a Voith-Siemens, alcançaram destaque na instalação de hidrelétricas, obtendo grande impulso nos seus negócios em virtude do crescente número de grandes empreendimentos hidrelétricos como as UHEs de Paulo Afonso, Três Marias, Furnas, Itaipu, Sobradinho, Tucuruí, Salto Osório, Salto Santiago, que conferiram ao período de 1970 e 1980 um grande salto na estruturação do parque gerador de setor hidrelétrico. 
No final dos anos de 1980 a crise internacional faz renascer as soluções de mercado legitimados teoricamente pela teoria neoliberal de Frederich Hayek (1944), cuja influência nos governos Thatcher, na Inglaterra, e Reagan nos Estados Unidos, será hegemônica. A crise econômica mundial, materializada pelo endividamento e descontrole fiscal e financeiro dos Estados, bem como a evolução crescente da inflação culminando com a estagnação econômica, servirá de campo fértil para o diagnóstico e o remédio neoliberal que afirma a necessidade do ajuste fiscal e do afastamento do Estado de setores que, aos olhos dessa teoria, são melhor geridos pelo mercado. Tais ideias serão experimentadas na América Latina através do Chile nos anos de 1980 durante o governo Pinochet (ANDERSERN, 1995).

No Brasil, a abertura democrática e a eleição de Fernando Collor de Melo marcaram o início do processo de reinserção da competitividade de mercado em setores estratégicos de infraestrutura no país. O Plano Nacional de Desestatização (PND) de 1990 deu diretrizes básicas para a organização da economia em todos os setores. A influência da concepção neoliberal foi contundente no Brasil, que teve um processo de privatização bastante vultuoso, cuja transferência de capital estatal para a esfera privada foi da ordem de $48,3 \%$, dos quais o setor de energia elétrica correspondeu a $31 \%$ (GONÇALVES JÚNIOR, 2007). Isso significa que a partir da década de 1990 as políticas de infraestrutura elétrica passarão a ter uma participação bastante importante da iniciativa privada.

No governo Fernando Henrique Cardoso a Lei no 8.987 / 1995 definia as linhas gerais sobre o regime de concessão e permissão da prestação de serviços públicos, cuja norma para outorga e prorrogação das concessões e permissões específicas para o setor hidrelétrico foram explicitados na Lei $n^{\circ}$ 9.074 / 1995. Por esta lei o Estado abre a possibilidade de se tornar parceiro da iniciativa privada na instalação de hidrelétricas, ou seja, inaugura-se o marco legal das Parcerias Público-Privadas (PPPs). Esse marco legal é ratificado através da Lei $n^{0} 11.079$ / 2004, já no governo Lula, que estabelece as normas gerais para as PPPs, sendo que os grandes projetos de infraestrutura e, particularmente, os de usinas hidrelétricas passam a ser conduzidos por Sociedades de Propósito Específico (SPE), criadas para cada empreendimento. A Lei $n^{\circ} 9.427$ / 1996, ao instituir a Agência Nacional de Energia Elétrica (ANEEL), confere ao Estado o papel de regulador do setor elétrico, pois assume as funções de regular e fiscalizar a produção, transmissão, distribuição e comercialização de energia elétrica, em conformidade com as políticas e diretrizes do governo federal.

A abundância fluvial somada ao predomínio do relevo planáltico possibilitou o desenvolvimento do sistema hidrelétrico brasileiro que passa por três estágios, um primeiro entre o final do século XIX até o início da década de 1930 com o predomínio da iniciativa privada: um segundo, da década de 1930 até o final de 1980, marcado pela estatização: e o período após da década de 1990, quando há um retorno da importância da iniciativa privada. 
Embora alguns autores, como Gonçalves Junior (2007) enfatizem fortemente essas distinções, é notório a inexistência de rupturas nessas três fases o que revela a convivência pacífica entre o estatal e o privado no setor elétrico. Isso não autoriza ignorar a existência de conflitos e disputas de interesse entre o Estado e o privado, contudo nos instiga a abordar o tema de forma mais complexa. Convém lembrar também que essa ausência de rupturas não significa a inexistência de tensões com a sociedade e os movimentos sociais que ora demandam melhores serviços, ora posicionam-se contra os impactos sociais e ambientais dos grandes empreendimentos hidrelétricos.

Esta questão é analisada na seção seguinte a partir da perspectiva da análise das políticas públicas.

\section{As políticas do setor elétrico no governo Lula}

A partir do final da década de 1970 inicia-se o processo lento e gradual de transição a democracia no Brasil, cuja consolidação ocorre com a elaboração da Constituição Cidadã de 1988 e as eleições diretas para presidente em 1989, que possibilitam a participação política e a disputa de bens, direitos e recursos para um conjunto de segmentos sociais antes alijados da sociedade política pelo regime ditatorial.

Já no final da década de 1970 e toda a década de 1980 o Brasil enfrenta um processo de endividamento externo e aumento exponencial da inflação que produziu um desequilíbrio fiscal e financeiro tão forte que o Governo Sarney decretou moratória da dívida externa. Em 1989 as eleições diretas elegem o presidente Fernando Collor de Melo, cujo mote de campanha era o combate aos privilégios no serviço público (os marajás) e a inserção do país na economia de mercado internacional, pois os governos militares tinham uma característica hegemonicamente intervencionista, conforme vimos anteriormente.

A partir do Governo Collor começa a se instalar no Brasil uma concepção da reforma do Estado para sanear as finanças públicas e estimular o crescimento econômico. Esta concepção, das políticas públicas, parte do diagnóstico de que a crise fiscal e financeira se deve a sua atuação inadequada quando intervém diretamente na economia ou quando investe em políticas sociais. Neste sentido, o remédio apresentado indica a necessidade de que o Estado afaste-se da economia e desenvolva políticas públicas eficientes, mantendo o equilíbrio orçamentário entre receita e despesa (BRESSER PEREIRA, 1997). Neste sentido as políticas públicas de infraestrutura não sofreram rupturas no governo Lula seguindo a concepção teórica reformista adotada no país a partir de Collor e consolidada com FHC.

As políticas de infraestrutura do setor elétrico podem ser interpretadas dentro do campo da análise de políticas públicas à luz do modelo do novo gerencialismo público. Para esta concepção a solução para os problemas de déficit fiscal, endividamento e estagnação econômica é a liberação da 
economia das amarras do Estado e a busca do equilíbrio financeiro através de políticas de contenção de gastos sociais e eficientes, conforme explicitado em outro texto (PASE e ROCHA, 2010).

Isto permite analisar a concepção das políticas públicas de infraestrutura a partir do modelo neoinstitucionalista e o regulatório, pois os compromissos assumidos pelos governos democráticos impediram rupturas entre si, embora o modelo da ditadura militar fosse completamente intervencionista e, portanto, distinto do atual.

O processo de reforma do Estado nos governos Collor e FHC retiraram várias prerrogativas e fontes de recursos do Estado com os quais o governo Lula não pôde contar. Não obstante, os compromissos eleitorais buscando a credibilidade internacional e o apoio eleitoral e legislativo interno, necessários para a construção da coalizão governista, assumidos por Lula, determinam limites para a ação política. Não houve rompimento de contratos e o processo de privatização e desmembramento do setor elétrico em unidades de negócios (geração, transmissão e distribuição), bem como o marco regulatório que definia a outorga e prorrogação das concessões e permissões. Essa característica direciona nosso olhar para o poder explicativo da abordagem neoinstitucionalista, para a qual as instituições possibilitam a previsibilidade e o ordenamento de comportamentos agregados e individuais. A ação do Governo Lula na política energética será no sentido de respeitar os contratos, as regras e aprofundar o processo anterior, ou seja, estimulando a iniciativa privada a agir no setor.

Neste sentido coube ao governo Lula incrementar as políticas públicas de infraestrutura energética regulamentando as Parcerias Público-Privadas (PPPs), sendo que os projetos de hidrelétricas passam a ser conduzidos por Sociedades de Propósito Específico (SPE) criadas em virtude de cada UHE a ser instalada e operada. Esta regulamentação consolida a política pública realizada através da delegação do Estado a instituições independentes, bem como viabiliza o financiamento dos empreendimentos, pois além de possibilitar que empresas públicas participem das SPE, compromete-se com seu financiamento. Não obstante, isso revela um paradoxo: ao mesmo tempo em que o processo de desregulamentação possibilita o acesso da iniciativa privada na produção e distribuição de energia elétrica, o Estado mantém uma participação decisiva como financiador dos empreendimentos intensivos em capital e tecnologia. Na prática o que ocorre é que a gestão dos negócios e administração dos lucros é transferida para a esfera privada, no entanto o Estado permanece viabilizando os empreendimentos intensivos em capital e tecnologia através da liberação ambiental e financiamento das obras.

Segundo o Banco Nacional de Desenvolvimento Econômico e Social BNDES, o papel da infraestrutura é de proporcionar benefícios em termos de crescimento econômico, mitigação da pobreza e sustentabilidade ambiental, no entanto isso ocorre somente quando presta serviços que atendem a demanda efetiva com eficiência. Cabe aos governos a responsabilidade de criar contextos legais e reguladores que amparem a participação do setor 
privado na provisão dos serviços de infraestrutura, o que materializa o sucesso da ação desse governo no setor elétrico já que o banco é um dos principais agentes públicos a atuarem no setor, financiando empreendimentos diretamente, através de empréstimos, ou indiretamente, constituindo-se como acionista das SPEs. Isso evidencia o potencial explicativo da abordagem neoinstitucionalista.

Outra possibilidade interpretativa é a do ciclo de política, cuja abordagem afirma que a definição da agenda é crucial para a elaboração e implementação das políticas públicas. Essa definição ocorre em vários momentos durante o processo político decisório, desde as eleições, na disputa nos legislativo, até a mobilização dos grupos de interesse, movimentos sociais e/ou a disputa e formação da opinião pública. É também o momento onde atuam vários atores ocultos tais como os burocratas e acadêmicos. Neste sentido é perfeitamente congruente a participação da burocracia, como ator oculto, na definição da concepção das políticas de infraestrutura do país. $\mathrm{Na}$ concepção do BNDES está presente o elemento que garante a agenda do setor elétrico: sua constituição estratégica como instrumento para impulsionar o crescimento econômico, alívio da pobreza e preservação ambiental.

\section{À guisa de conclusão}

Ao considerar a abordagem dos estilos políticos, percebe-se pouca inovação na sua utilização para analisar as políticas públicas contemporâneas no Brasil. Ainda se está fortemente vinculado às formulações clássicas de Gilberto Freyre, Sérgio Buarque de Holanda, Raimundo Faoro, José Murilo de Carvalho, Roberto DaMatta que contribuíram inexoravelmente para a explicação do país com suas categorias de clientelismo, paternalismo, patrimonialismo, estamento, jeitinho, cordialidade, sincretismo cultural. Não obstante, é importante perceber que, no período contemporâneo a sociedade brasileira enfrenta uma complexidade que impõe avançar na elaboração e, de outro lado, reconhecer a sua capacidade explicativa.

É inegável a capacidade dessa abordagem explicar as políticas do setor elétrico, particularmente no que tange ao aspecto da legitimação do formato de definição da agenda política, que estabelece um ordenamento de prioridades onde no topo está o crescimento econômico e o processo de reinvenção capitalista e mercadológica e, na outra ponta, os interesses de segmentos sociais que sequer tiveram acesso a ganhos proporcionados por revoluções burguesas do século XIX como, por exemplo, o acesso dos agricultores à propriedade privada da terra.

Embora em democracias a legitimidade seja formalmente construída pela consolidação institucional, no Brasil é inegável a influência de elementos relacionados à cultura política, como a invisibilidade de segmentos sociais e ou interesses contraditórios ao status quo. É revelador o fato de somente em 2010 consolidar-se o reconhecimento do conceito de "atingido" por grandes empreendimentos hidrelétricos (Decreto Presidencial n 7.342 / 2010) que, 
desde a década de 1980, era definida via Termo de Ajustamento de Conduta (TAC), regramento precário estabelecido para cada empreendimento (SPE) por pressão do Movimento de Atingidos por Barragens (MAB), com a participação do Estado, através do Instituto Brasileiro de Meio Ambiente (IBAMA) e por iniciativa do Ministério Público.

Isso revela o elitismo político brasileiro que se justifica em razão da necessidade do crescimento econômico, cujas inflexões ocorrem somente por incorporação após pressão dos segmentos de interesse alijados. É bem verdade que no primeira década do século XXI houve uma retomada do investimento em políticas sociais e de desenvolvimento que, no entanto, não ameaçam em nada a tese central que demonstra que o país possui um ambiente atraente para qualquer investimento.

A abordagem dos estilos políticos possibilita perceber a perspectiva elitista do sistema político decisório, de um lado, e a relação paternalista e clientelista, de outro, aliado à implementação de políticas sociais compensatórias com objetivo de legitimação do status quo que determinam a agenda do setor elétrico, cujas marcas no período contemporâneo são a aversão às rupturas e consequênte permanência para garantir a prestação de serviço que, numa ambiente crescentemente mercadológico e competitivo, necessita atrair investimentos e garantir sua acumulação.

Hemerson Luiz Pase é Doutor em Ciência Política pela Universidade Federal do Rio Grande do Sul, Professor do Programa de Pós-Graduação em Ciência Política e Coordenador do Núcleo de Estudos em Políticas Públicas (NEPPU) da Universidade Federal de Pelotas.

E-mail: hlpase@yahoo.com.br

\section{Referências}

ANDERSERN, Perry. Balanço do neoliberalismo. In: SADER, Emir; GENTILLI, Pablo (Orgs.). Pós neoliberalismo: as políticas sociais e o estado democrático. Rio de Janeiro: Paz e Terra, 1995. p. 9-23.

ANEEL. Atlas de energia elétrica do Brasil. Brasília: Aneel, 2008.

BAQUERO, Marcelo; PRÁ, Jussara. A democracia brasileira e a cultura política no Rio Grande do Sul. Porto Alegre: UFRGS, 2007.

BRESSER PEREIRA, Luiz Carlos. Estratégia e estrutura para um novo Estado. Revista de Economia Política, São Paulo, v. 17, n. 3, p. 24-38, set. 1997.

DI GIOVANNI, Geraldo. As estruturas elementares das políticas públicas. Caderno de Pesquisa [do] NEPP/UNICAMP, Campinas, n. 82, p. 1-29, 2009. 
FARIA, Carlos Aurélio. Idéias, conhecimento e políticas públicas: um inventário sucinto das principais vertentes analíticas recentes. Revista Brasileira de Ciências Sociais, São Paulo, v. 18, n. 51, p. 22-29, fev. 2003.

FREY, Klaus. Políticas Públicas: um debate conceitual e reflexões referentes à prática da análise de políticas públicas no Brasil. Planejamento e Políticas Públicas, Brasília, n. 21, p. 1-21, jun. 2000.

GONÇALVES JÚNIOR, Dorival. Reformas na Indústria Elétrica Brasileira: A Disputa pelas 'Fontes' e o Controle dos Excedentes. 2007. 416 f. Tese (Doutorado em Energia) - Programa Interunidades de Pós-Graduação em Energia, Universidade de São Paulo, São Paulo, 2007.

LEME, Alessandro André. A reforma do setor elétrico no Brasil, Argentina e México: contrastes e perspectivas em debate. Revista Sociologia e Política, Curitiba, v. 17, n. 33, p. 97-121, jun. 2009.

LOWI, Theodor. American Business, Public Policy, Case Studies and Political Theory. World Politics, Cambridge, v. 16, n. 4, p. 677-715, jul. 1964.

. Four Systems of Policy, Politics, and Choice. Public Administration Review, Washington, D.C., v. 32, n. 4, p. 298-310, jul.-ago. 1972.

MELO, Marcos André; SILVA, Pedro Luiz. O processo de implementação de políticas públicas no Brasil: características e determinantes da avaliação de programas e projetos. Caderno de Pesquisa [do] NEPP/UNICAMP, Campinas, n. 48, p. $1-16,2000$.

OLIVEIRA, José Antônio. Desafios do planejamento em políticas públicas: diferentes visões e práticas. Revista da Administração Pública, Rio de Janeiro, v. 40, n. 40, p. 273-288, mar.-abr. 2006.

PASE, Hemerson Luiz; ROCHA, Humberto José. O governo Lula e as políticas públicas do setor elétrico. Revista Debates, Porto Alegre, v. 4, n. 2, p. 32-59, jul.-dez. 2010.

REIS, Elisa. Reflexões leigas para a formulação de uma agenda de pesquisa em políticas públicas. Revista Brasileira de Ciências Sociais, São Paulo, v. 18, n. 51, p. 11-14, fev. 2003.

RODRIgUeS, Marta Maria. Políticas Públicas. São Paulo: Publifolha, 2010.

ROMANO, Jorge Osvaldo. Política nas políticas: um olhar sobre a agricultura brasileira. Rio de Janeiro: Mauad, 2009. 
SOUZA, Celina. Políticas Públicas: uma revisão da literatura. Sociologias, Porto Alegre, ano 8, n. 16, p. 20-45, jul.-dez. 2006.

TREVISAN, Andrei Pittol; BELLEN, Hans Michael. Avaliação de políticas públicas: uma revisão teórica de um campo em construção. Revista de Administração Pública, Rio de Janeiro, v. 42, n. 42, p. 529-550, maio-jun. 2008.

Texto recebido em 30/04/2012.

Aprovado em 04/07/2012. 